TURIZAM

Volume 16 , Issue 3

102-112 (2012)

\title{
The Strength and Dynamics of the Seasonal Concentration in Montenegrin Tourism
}

\author{
Miloš Bigović* \\ Received: May 2012 | Accepted: July 2012
}

\begin{abstract}
The purpose of this paper is to describe and analyse the seasonal concentration in Montenegrin tourism by means of the Gini coefficient. This method is applied to two monthly time series - tourist arrivals and tourist overnight stays, covering the period 2001-2011. Regarding the strength and dynamics of the seasonal concentration, the results of the study revealed the existence of strong as well as constant seasonality in Montenegrin tourism. Namely, the Gini coefficient for tourist arrivals ranges from 0.54 to 0.61 , while for tourist overnight stays it goes from 0.61 to 0.67 . In such unfavourable circumstances, Montenegro as a tourist destination should strongly focus on reducing strong and constant seasonality.
\end{abstract}

Key words: Seasonality, Gini coefficient, Tourist arrivals, Tourist overnight stays

\section{Introduction}

Each tourist destination experiences some kind of temporal imbalance in its physical and financial parameters, which may occur on a daily, weekly, monthly, quarterly or annual basis. This phenomenon is called seasonality, and is regarded 'as one of the most visible characteristics of modern tourism' (Bigović, 2OII, I6). Simply stated, tourism seasonality represents a special kind of dependence and 'is often seen as a major problem that this industry has to face' (Fernández-Morales, 2003, 942). Seasonal concentration is a much-debated question in contemporary tourism research. A great number of studies have been conducted on the relationship between tourism and seasonality (see Ashworth, Thomas, I999; Bigović, 2OII; Chung, 2009; Fernández-Morales, 2003; Kennedy, I999; Koenig-Lewis, Bischoff, 2005; Lim, McAleer, 2OOI; Nadal et al., 2004; Sutcliffe, Sinclair, I980). In this respect, the purpose of this paper is to describe and analyse the seasonal concentration in Montenegrin tourism by means of the Gini coefficient (see Arnold, 2008). Using appropriate data, this method is applied to two time series: number of tourist arrivals and number of tourist overnight stays. As a summer destination, Montenegro strongly bases its tourism product on sun and sea and accordingly it is very interesting to observe its seasonal pattern over time.

Following Bigović (2OII), in order to describe and analyse seasonality in tourism the researchers must take two issues into considerations: the strength and the dynamics of the

* Nikole Ljubibratića 46/c, 85340 Herceg-Novi, milos.bigovic@t-com.me, 0038269013322 
seasonal concentration. Hence, the first research objective is to show how strong the seasonal pressure in Montenegrin tourism is (i.e., whether it is strong or weak). Parallel, the second research objective is to reveal the dynamics of seasonality over time (i.e., whether it is constant or non-constant). Moreover, the results of the study are expected to be useful for various destination management organizations. Therefore, the contributions of this paper are twofold. Firstly, the paper analyses the strength and dynamics of seasonality in Montenegrin tourism. Secondly, the study assists destination managers in understanding the key features of the seasonal concentration in Montenegrin tourism.

The article proceeds as follows. After the brief introduction part, a review of the literature on tourism seasonality and some facts regarding seasonality in Montenegrin tourism are presented. The third part of the paper provides a full description of the study method. After that, the study results are presented. Finally, some concluding remarks are given in the last part of the paper.

\section{Background}

\section{Seasonal concentration in tourism}

In general, 'seasonality is the systematic, although not necessarily regular, intra-year movement caused by the changes of the weather, the calendar and timing of decisions, directly or indirectly through the production and consumption decisions made by the agents of the economy' (Hylleberg, I992, 4). According to Fernández-Morales (2003), there are many definitions of tourism seasonality. For instance, Butler (2OOI, 5) described seasonality in tourism 'as a temporal imbalance in the phenomenon of tourism, which may be expressed in terms of dimensions of such elements as numbers of visitors, expenditure of visitors, traffic on highways and other forms of transportation, employment and admissions to attractions'. Following Cooper et al. (2008, 686), seasonality refers to the 'temporal fluctuations of tourism on a daily, weekly, monthly or annual basis'. Along the same line, Biedermann (2008, 4I) stated that seasonality is 'a prevalent characteristic in travel and tourism marked by sharp variations in demand depending on the time of the year'. In this sense, Allcock (I989, 387) defined tourism seasonality as 'the tendency of tourist flows to become concentrated into relatively short periods of the year'. The stated definitions point out the oscillations in tourism, and in order to describe them, Bigović (2OII, I7) defined seasonality in tourism according to two oscillation types - 'strength and dynamics of seasonality'.

There are two causes of tourism seasonality - natural and institutionalized (BarOn, 1975). Natural is a result of nature and its forces, related to the elements of weather and climate. According to Koenig-Lewis and Bischoff (2005), these factors are predictable and recur with only small changes. On the other hand, institutionalized seasonality remains in the domain of people and is associated with legislation, religion, custom, historic conventions et cetera. For instance, school and public holidays produce institutional seasonality. Beside these two basic causes, there are some additional sources of seasonality in tourism - social pressure, fashion, imitation, inertia, tradition et cetera.

Tourism seasonality is usually seen as a negative phenomenon and 'is treated as a weakness or a problem, not only in economic sense, but also in socio-cultural and ecological' (Bigović, 2OII, I7). Precisely, economic problems are related to the loss of profit due to the inefficient use of resources, low returns on capital, difficulties with employment (i.e., small 
chances of recruiting and retaining full-time employees), a shortage of quality rooms during the main season et cetera (see Koenig-Lewis, Bischoff, 2005; Chung, 2009, for discussion). Socio-cultural problems include congestion, overcrowding, significant increases in the cost of community services, noise, increased crime due to a higher number of people, extra police, sanitary and health personnel, increased risks of accidents, possibility of negative influences on the traditional way of life et cetera (see Koenig-Lewis, Bischoff, 2005; Chung, 2009, for discussion). Bender et al. (2005) believe that ecological problems contain pollution problems and exhaustion of the natural resources. Namely, the seasonal concentration in tourism may cause 'overuse as well as under-utilization of resources and facilities' (Bender et al., 2005, 304). Consequently, tourist destinations are trying to reduce seasonality and avoid negative effects. According to Wall and Mathieson (2006, 58), 'they do this by reducing prices, attempting to attract visitors, such as senior citizens who have more flexible schedules, and by developing special events. Most of the effort so far has been placed on manipulating the supply side in an attempt to make destinations more attractive in off-peak periods'. On the other side, Butler (2OOI, 6) stated that a "very little research has been done to explore any of the positive aspects of seasonality". In spite of that, there are positive effects - each year's rest period may be beneficial for majority of natural resources, where off-peak season provides a chance for recovery. Additionally, local communities can preserve their own identity through time.

\section{Seasonal concentration in Montenegrin tourism}

According to Nadal et al. (2004), in many cases the simple plot of time series can be useful to get a first impression of the seasonal concentration. Using this kind of graphical representation, the researchers can reveal some very important properties of destination seasonality. For instance, it is easy to see the distinction between main and off-peak season as well as the length of the two shoulder seasons. Further, any non-standard data can be easily spotted. In addition, the strength and dynamics of the seasonal concentration could be roughly assessed. Along this line of reasoning, the evolution of tourist arrivals and tourist overnight stays in Montenegro, from 2OOI to 2OII, is explored within two figures below.

\section{Tourist arrivals in Montenegro}

Figure I shows the yearly number of tourist arrivals in Montenegro. Firstly, graphical representation reveals that seasonality has a peak in July and August. Consequently, these two months are considered as the main season. On the contrary, it is visible that January, February, March, April, October, November and December refer to the off-peak season in Montenegrin tourism. Rest of the year can be treated as a shoulder season. The first one is between May and June, while the second shoulder season is during September. Further, the depiction of tourist arrivals shows no extreme and unusual specificities in the data. ${ }^{1}$ With respect to the strength and dynamics, the seasonal concentration in Montenegrin tourism seems to be strong and constant (i.e., tourist arrivals are dominantly concentrated in a few months of the year - May, June, July, August and September).

1 This is important because only economic impacts have been affected the time series. 


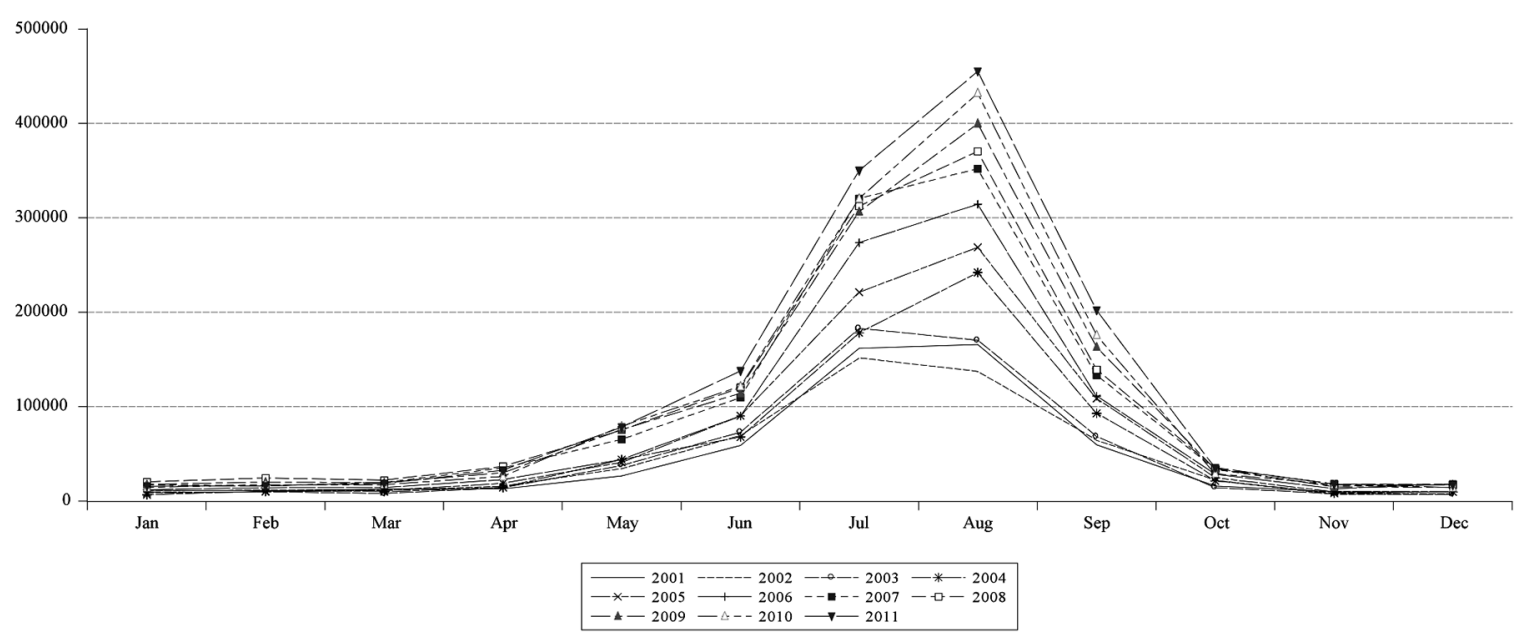

Figure 1. Yearly number of tourist arrivals in Montenegro: 2001-2011

\section{Tourist overnight stays in Montenegro}

On the other side, Figure 2 shows the yearly number of tourist overnight stays in Montenegro. First of all, graphical representation reveals that seasonality has a peak during two summer months - July and August. Again, these two months represent the main season in Montenegrin tourism. Further, it is visible that one shoulder season is during May and June, while September is another shoulder season. January, February, March, April, October, November and December refer to the off-peak season. Figure 2 also shows no extreme and unusual data in number of tourist overnight stays. As in the previous case, seasonality in Montenegrin tourism seems to be strong and constant (i.e., tourist overnight stays are dominantly concentrated in a few months of the year - May, June, July, August and September).

Based on the previous discussion, two moments should be considered in order to describe and analyse the seasonal concentration. The first moment refers to the fact whether the seasonality in Montenegrin tourism is strong or not. Following Bigovic (2OII) there is not any theoretical 'critical limit' suggesting a clear difference between strong and non-strong sea-

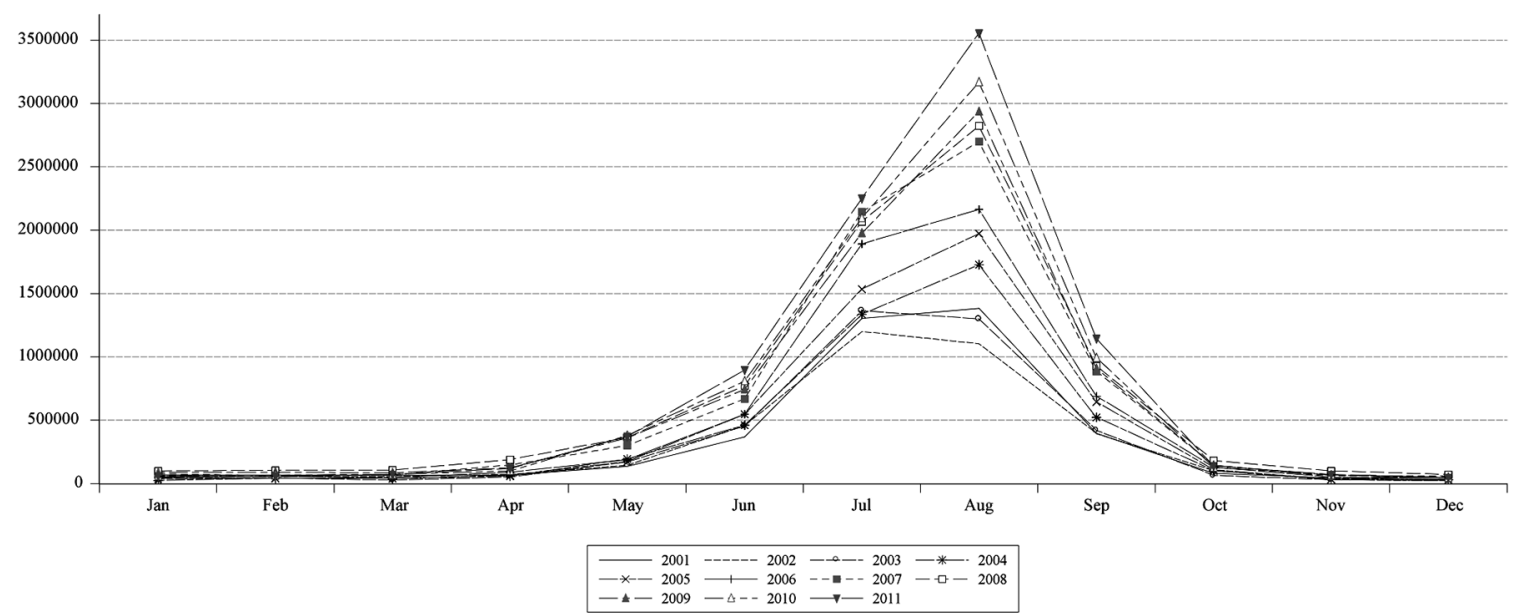

Figure 2. Yearly number of tourist overnight stays in Montenegro: 2001-2011 
sonality in tourism. However, for the purpose of this paper and according to the Gini coefficient, the suggestion for that limit is proposed to be at 0.5 . Concretely, if the value of the Gini coefficient is over 0.5 the seasonal concentration should be regarded as strong and vice versa. As already stated, the simple plots suggest that the seasonal concentration in Montenegrin tourism seems to be strong. Thus, the first hypothesis read (HI):

According to number of arrivals and overnight stays, the seasonal concentration in Montenegrin tourism is strong (i.e., all values of the Gini coefficients are over 0.5).

The second moment refers to the fact whether the seasonality in Montenegrin tourism is constant or not. Again, Bigović (2OII) stated that there is not any theoretical method suggesting a procedure for testing whether the seasonality in tourism is constant or non-constant. In spite of that, the author suggested that a visual comparison could be helpful. With respect to the Gini coefficient, if all calculated values graphically approximate a constant level, with just negligible variations, the seasonal concentration should be regarded as constant and vice versa. As previously stated, the simple plots suggest that the seasonal concentration in Montenegrin tourism seems to be constant. Thus, the second hypothesis read (H2):

According to number of arrivals and overnight stays, the seasonal concentration in Montenegrin tourism is constant (i.e., all values of the Gini coefficient graphically approximate a constant level with just negligible variations).

\section{Method}

As expected, an appropriate measuring method is needed in order to describe and analyse the seasonal concentration in tourism. Following Nadal et al. (20O4), the Gini coefficient has been the most used.

The well-known Gini coefficient is 'a statistical measure of inequality' (Black, 2002, I97) and 'is derived from the Lorenz curve' (Lundtorp, 200I, 30). Precisely, the famous Lorenz curve is a graphical representation of inequality while the Gini coefficient is a measure for this inequality. For complete equality (i.e., the same number of tourist arrivals or tourist overnight stays every month), which is an extreme situation, the Lorenz curve would be a straight line (i.e., represents $45^{\circ}$ equality line) and it becomes more curved as inequality rises (Black, 20O2, 279). On the other side, the Gini coefficient is a number between $\mathrm{O}$ and I (i.e., $\mathrm{O} \leq \mathrm{G} \leq \mathrm{I}){ }^{2}$ The larger the Gini coefficient, the greater the inequality (i.e., seasonality in Montenegrin tourism) and the smaller the Gini coefficient, the lower the inequality (i.e., seasonality in Montenegrin tourism) (see Arnold, 2008, 578). More specifically, in tourism industry the Lorenz curve shows 'the cumulated frequencies in rank with the lowest frequency (winter month) to the left and the month with the highest number of visitors to the right. With the same number of visitor every month, the Lorenz curve would be a straight line, the line of equality. The more unequal the seasonal distribution of visitors, the larger will be the area between the Lorenz curve and the line of equality (i.e., straight line). The Gini coefficient is calculated as the area between the curve and the $45^{\circ}$ equality line divided by the entire area below the $45^{\circ}$ line' (Lundtorp, 2OOI, 30). This concept is theoretically represented in Figure 3.

\footnotetext{
2 G denotes the Gini coefficient.
} 


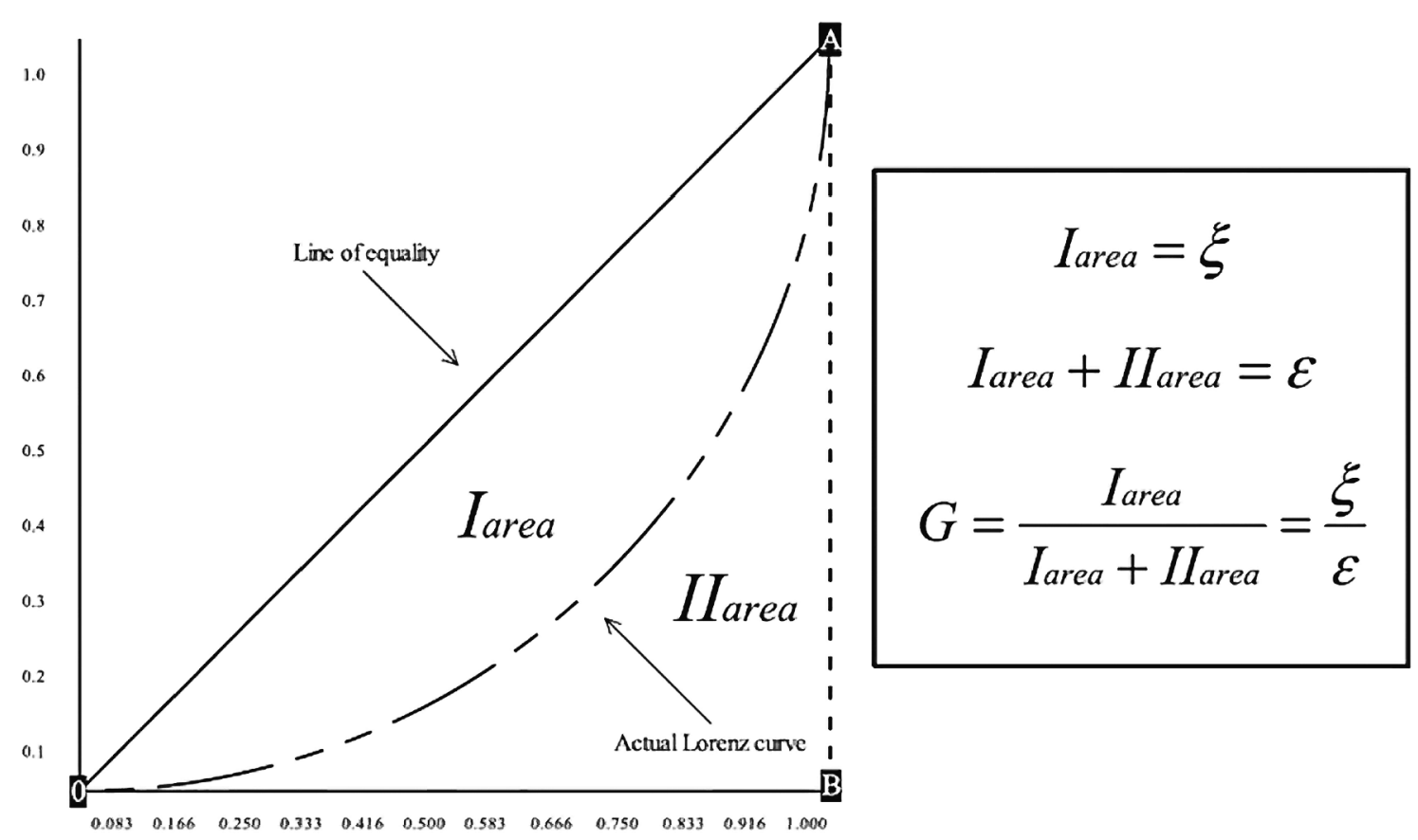

Figure 3. The Gini coefficient

Correspondingly, the Gini coefficient in Montenegrin tourism is equal to the area between the line of equality (OA) and the actual Lorenz curve $\rightarrow \mathrm{I}_{\text {area }}=\xi$, divided by the entire triangular area $(\mathrm{OAB}) \rightarrow \mathrm{I}_{\text {area }+} \mathrm{II}_{\text {area }}=\varepsilon$ under the line of equality. As shown in Figure 3, the area $\xi$ is divided by the triangular area $\varepsilon$. Then, the Gini coefficient $G$ related to Montenegrin tourism in the year $\mathrm{t}$ can be calculated as follows: $\mathrm{Gt}=\xi \div \varepsilon$. The closer value of the Gini coefficient to zero means the smaller seasonality in Montenegrin tourism and the closer value of the Gini coefficient to one means the stronger or greater seasonality in the destination.

\section{Results}

\section{Tourist arrivals}

Eleven Lorenz curves, each representing one year, along with the line of equality are shown in Figure 4. Their resemblance is clear, which suggests that Gini coefficients are similar in value. Moreover, the first impression brings to mind a probable degree of the seasonal concentration in Montenegrin tourism. In fact, the Lorenz curves are far away from the line of equality, which implies that large values of the Gini coefficients in Montenegrin tourism can be expected.

Table I reveals all calculated values of the Gini coefficients in Montenegrin tourism. All figures point out a pronounced seasonality in the number of tourist arrivals. The highest obtained value of the Gini coefficient is about O.6I and the lowest one is about 0.54. All values of the Gini coefficients are over 0.5. This strongly supports our hypothesis Hi that the seasonal concentration in Montenegrin tourism is strong. 


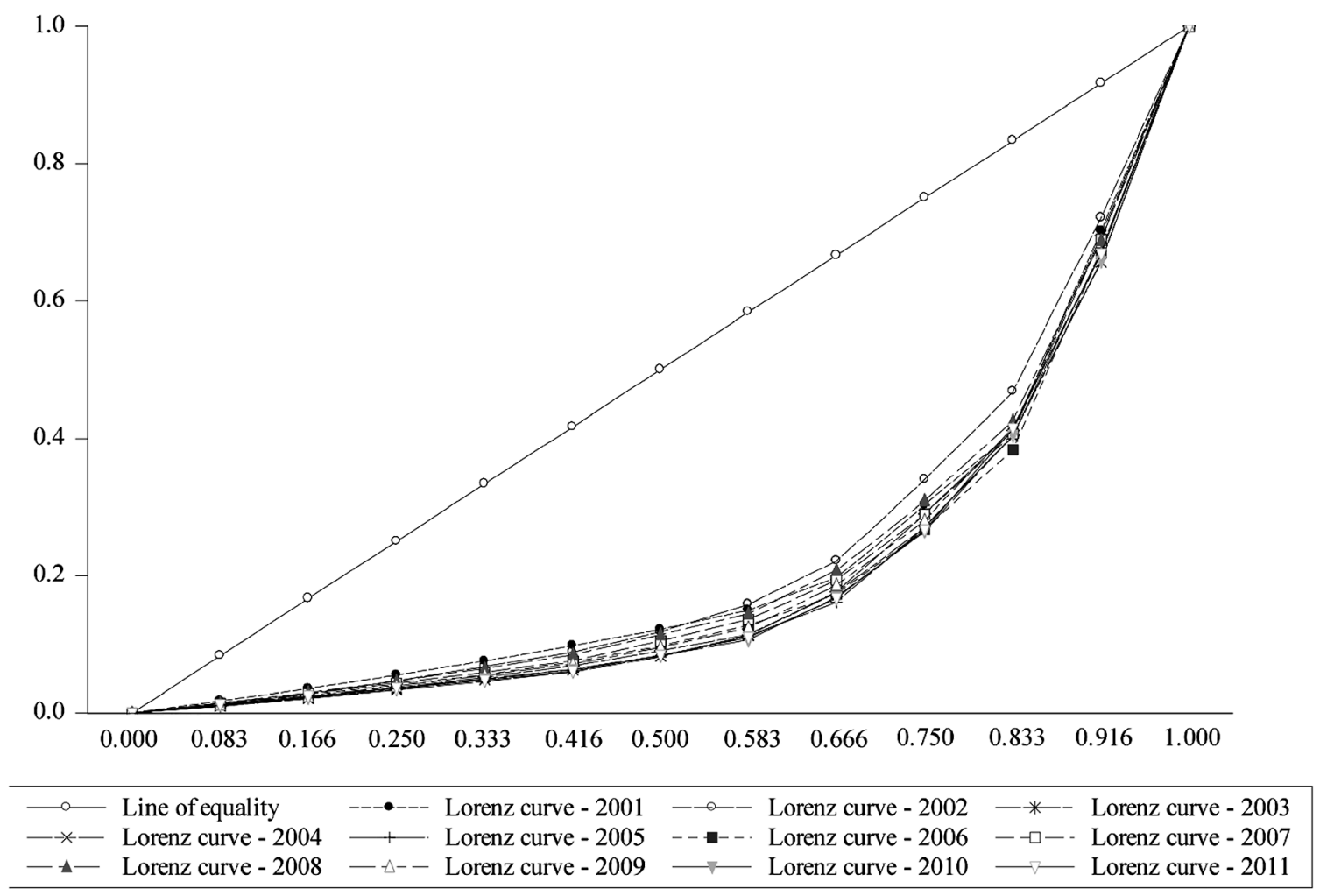

Figure 4. Lorenz curves - Number of tourist arrivals in Montenegro: 2001-2011

Table 1. Evolution of the Gini coefficient: Tourist arrivals in Montenegro (2001-2011)

\begin{tabular}{|c|c|c|c|c|c|c|c|c|c|c|c|}
\hline & 2001 & 2002 & 2003 & 2004 & 2005 & 2006 & 2007 & 2008 & 2009 & 2010 & 2011 \\
\hline G & 0.56 & 0.54 & 0.59 & 0.60 & 0.61 & 0.60 & 0.58 & 0.56 & 0.59 & 0.61 & 0.60 \\
\hline
\end{tabular}

Source: Author's calculations

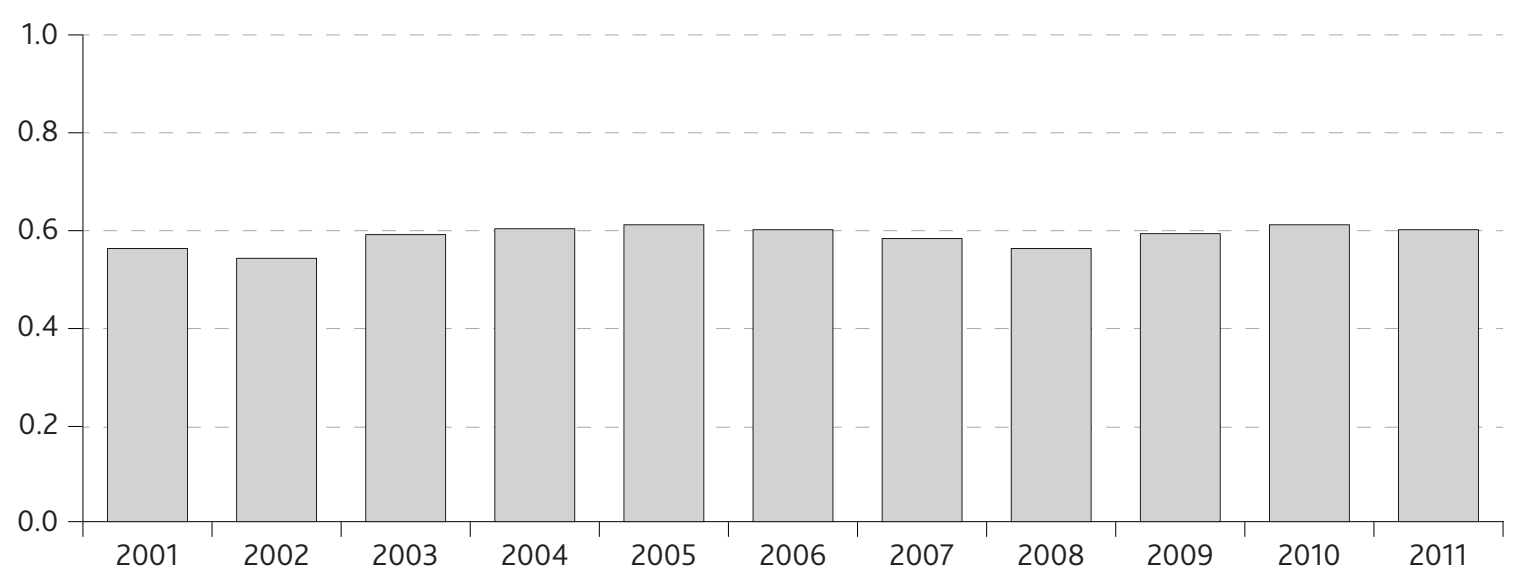

Figure 5. Comparison of the Gini coefficient: Tourist arrivals in Montenegro (2001-2011) 
On the other side, Figure 5 visually shows the values of the Gini coefficients in Montenegrin tourism. All calculated results are very stable and graphically approximate a constant level with just negligible variations, which implies that seasonality is constant. This strongly supports our hypothesis $\mathrm{H}_{2}$ that the seasonal concentration in Montenegrin tourism is constant.

\section{Tourist overnight stays}

Again, the Lorenz curves, each for one year, along with the line of equality are outlined in Figure 6. Obviously, their resemblance is apparent, which again suggests that the Gini coefficients are pretty similar in its value. Additionally, all Lorenz curves are far away from the line of equality implying again that the large values of the Gini coefficients in Montenegrin tourism can be expected.

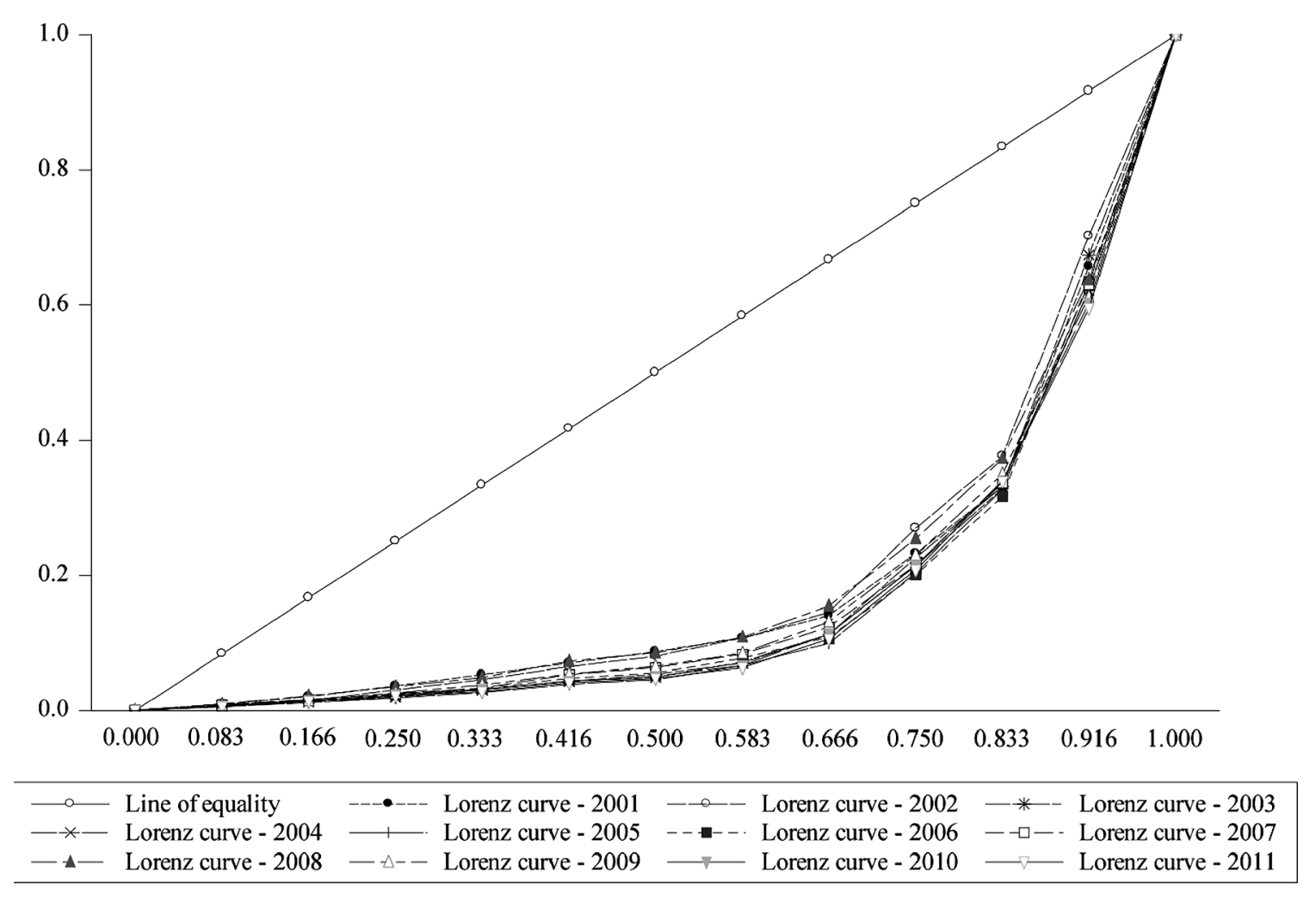

Figure 6. Lorenz curves - Number of tourist overnight stays in Montenegro: 2001-2011

Table number 2 shows all calculated values of the Gini coefficients in Montenegrin tourism. All figures reveal a pronounced seasonality in the number of tourist overnight stays. The highest obtained value of the Gini coefficient is about 0.67 and the lowest one is about o.6I. Again, all values of the Gini coefficients are over 0.5, and this strongly supports our hypothesis Hi that the seasonal concentration in Montenegrin tourism is strong. 
Table 2. Evolution of the Gini coefficient: Tourist overnight stays in Montenegro (2001-2011)

\begin{tabular}{|c|c|c|c|c|c|c|c|c|c|c|c|}
\hline & 2001 & 2002 & 2003 & 2004 & 2005 & 2006 & 2007 & 2008 & 2009 & 2010 & 2011 \\
\hline G & 0.63 & 0.61 & 0.65 & 0.66 & 0.67 & 0.66 & 0.65 & 0.62 & 0.65 & 0.67 & 0.67 \\
\hline
\end{tabular}

Source: Author's calculations

Figure 7 visually shows the values of the Gini coefficients in Montenegrin tourism. All calculated values are stable. The results graphically approximate a constant level with just negligible variations, which again implies that seasonality is constant. This strongly supports our hypothesis $\mathrm{H} 2$ that the seasonal concentration in Montenegrin tourism is constant.

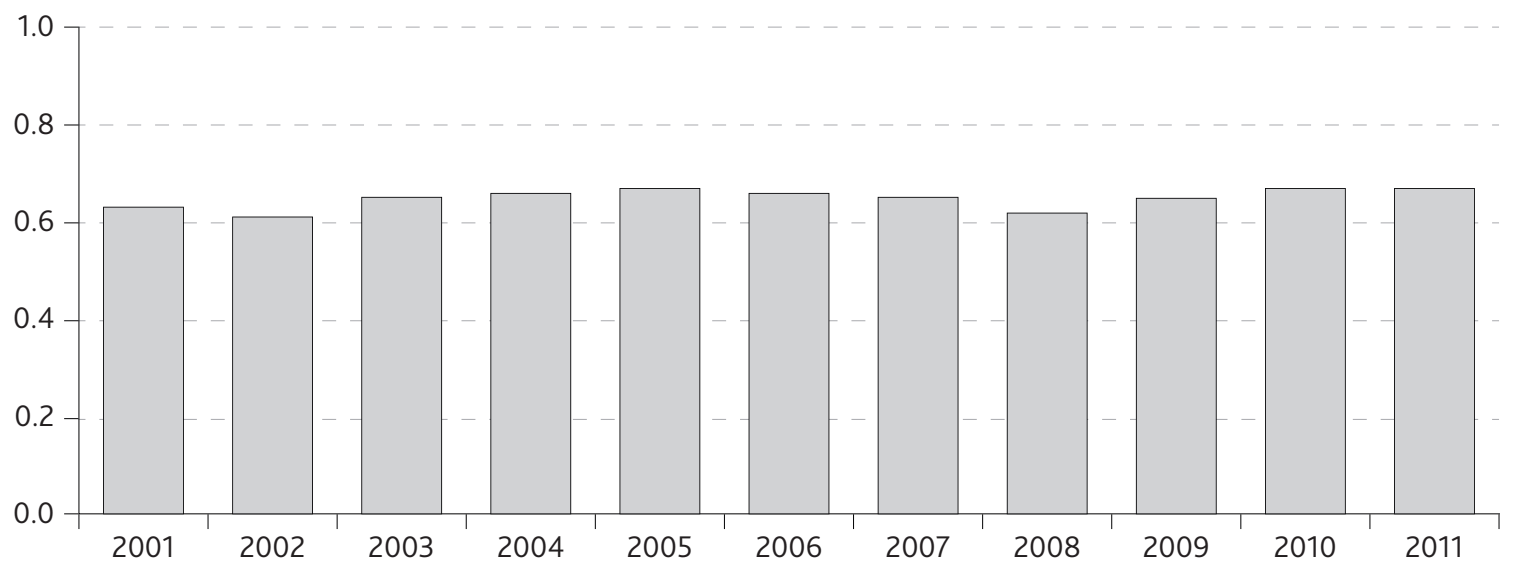

Figure 7. Comparison of the Gini coefficient: Tourist overnight stays in Montenegro (2001-2011)

According to the study results, all calculated values of the Gini coefficients are over 0.5, which enables us to accept the hypothesis HI as correct. Furthermore, all quantified values approximate a constant level, with only negligible variations. Thus, we accept the hypothesis $\mathrm{H} 2$ as correct as well.

\section{Conclusion}

The acceptance of hypotheses has several implications related to Montenegrin tourism. Some of the most important are the following.

Because of the strong seasonality, there is no balance in Montenegrin tourism. During the main season there is overuse of resources (i.e., number of tourists highly exceeds the carrying capacity limit) and during the two shoulder seasons there is under-utilization of resources (i.e., carrying capacity limit exceeds the number of tourists). Accordingly, the tourist product sustainability is under threat during the peak season. The solution to this problem lays in reducing the seasonal concentration in Montenegrin tourism. The degree of seasonality should be approximately adequate to the destination carrying capacity limit.

Further, a huge problem in Montenegrin tourism is a black market - a direct and negative effect of strong and constant seasonality. Due to a large number of visitors and many economic activities during the main season, it is hard to control all participants in the market. A strong seasonality 'prevents' the authorities to take proper and planned activity in order to reduce the black market. The peak season is too short to enable an adequate action. There- 
fore, a long run quality of tourist product is questionable. The solution to this problem is not in reducing the black market itself, because it is impossible. The solution is in reducing the seasonal concentration in Montenegrin tourism, which will gradually reduce many illegal activities in the destination, because of the better business environment.

Montenegrin tourism also faces some problems related to tourism employment, which are yet another direct consequence of strong and constant seasonality. In fact, there is a paradoxical situation. The majority of employees are foreigners, while residents are not eager to work although the unemployment rate is high. The cause of that situation is very short working period due to a strong seasonal concentration. On the other hand, employers are not ready to recruit and retain full-time employees, again due to a strong seasonal concentration. Accordingly, the solution to this problem requires the longer season that will motivate both employers and employees to find common interests.

Because of a strong and constant seasonality, Montenegro is considered as coastal and mass, rather then selective and exclusive tourist destination. Actually, the current situation is far away from desired destination image (see Montenegro tourism development strategy to 2O2O) and, above all, from real potentials - based on diversity and quality of natural and artificial resources. Without reducing the extent of the seasonal concentration, it will be very hard to create and maintain a competitive and sustainable tourist product in Montenegro.

In such unfavourable circumstances, Montenegro as a tourist destination should strongly focus on reducing seasonality. In order to reduce such strong and constant seasonal concentration in Montenegrin tourism several issues need to be addressed - structure of accommodation establishments, destination pricing policy, tourist product diversification as well as better flight connections.

\section{References}

Allcock, J.B. (1989). Seasonality. In S.F. Witt \& L. Moutinho (Eds.), Tourism marketing and management handbook, Prentice Hall, London, 387-392.

Arnold, R.A. (2008). Economics, Cengage Learning, Mason.

Ashworth, J., Thomas, B. (I999). Patterns of seasonality in employment in tourism in the UK. Applied Economics Letters 6(II), 735-739.

BarOn, R.R.V. (I975). Seasonality in tourism: a guide to the analysis of seasonality and trends for policy making, The Economist Intelligence Unit, London, Technical Series No. 2.

Bender, O., Schumacher, K.P., Stein, D. (2005). Measuring seasonality in Central Europe's tourism - how and for what?” Talk: CORP 2005 - GeoMultimedia 05, in IOth International Conference on Information \& Communication Technologies (ICT) in Urban Planning and Spatial Development and Impacts of ICT on Physical Space, Wien, 3O3-309.

Biederman, P.S. (2008). Travel and tourism: an industry example, Pearson Education, Upper Saddle River.

Bigović, M. (2OII). Quantifying seasonality in tourism: a case study of Montenegro, Academica Turistica: Tourism \& Innovation Journal 4(2), I5-32.

Black, J. (20O2). A dictionary of economics, Oxford University Press, NewYork.

Butler, R.W. (2OOI). Seasonality in tourism: issues and implications. In T. Baum \& S. Lundtorp (Eds.), Seasonality in tourism, Elsevier Science, Oxford, 5-22.

Chung, J.Y. (2009). Seasonality in tourism: a review, e-Review of Tourism Research 7(5), 82-96. 
Cooper, C., Wanhill, S., Fletcher, J., Gilbert, D., Fyall, A. (2008). Tourism: principles and practice, Pearson Education, Harlow.

Fernández-Morales, A. (2003). Decomposing seasonal concentration, Annals of Tourism Research 3O(4), 942-956.

Hylleberg, S. (I992). General introduction, in S. Hylleberg (Ed.), Modelling seasonality, Oxford University Press, Oxford, 3-I4.

Kennedy, E.L. (I999). Seasonality in Irish tourism, I973-I995, Tourism Economics 5(I), 25-47.

Koenig-Lewis, N., Bischoff, E. (2005). Seasonality research: the state of the art, International Journal of Tourism Research 7(4-5), 2OI-2I9.

Lim, C., McAleer, M. (2OOI). Monthly seasonal variations: Asian tourism to Australia, Annals of Tourism Research 28(I), 68-82.

Lundtorp, S. (2OOI). Measuring tourism seasonality, in T. Baum \& S. Lundtorp (Eds.), Seasonality in tourism, Elsevier Science, Oxford, 23-50.

Ministry of tourism and environment (2008). Montenegro tourism development strategy to 2O2O, Podgorica.

Nadal, J.R., Font, A.R., Rosselló, A.S. (2004). The economic determinants of seasonal pattern, Annals of Tourism Research 3I(3), 697-7II.

Sutcliffe, M.S., Sinclair, M.T. (I980). The measurement of seasonality within the tourist industry: an application to tourist arrivals in Spain, Applied Economics I2(4), 429-44I.

Wall, G., Mathieson, A. (2006). Tourism: change, impacts and opportunities, Pearson Education, Harlow. 